\title{
"Why not? But I can't" - Influence of a 'culture of poverty' on learning - A case study
}

\author{
Marie Perera \\ Department of Humanities Education \\ University of Colombo, Colombo
}

\begin{abstract}
Based on a sub set of data from a study which investigated the role of motivation as a contributing factor in second language learning in a disadvantaged school setting in Sri Lanka, this paper attempts to show the relationship between a 'culture of poverty' and learning.

Lewis, (1970 : p.85) states that 'in addition to being a condition of chronic economic poverty, the culture of poverty is characterized by the cognitive poverty of its 'members', instilling a fatalism with reference to any possibility of ever achieving a different way of life'. Although education is one way in which such people could be empowered to develop a sense of self confidence and self worth, children acquire the adult fatalism early and become learned helpless.

The findings of the study indicate that there is a correlation between motivation and a 'culture of poverty'. Further, in spite of the adverse socio-economic backgrounds from which the students come, their motivation to learn the second language can be enhanced. However, it is not the 'culture of poverty' per se that affects motivation but the type of attributions that the students make regarding their prior learning experiences. Thus a relationship between attributions and 'cognitive poverty' was visible.
\end{abstract}

\section{Introduction}

Education was once considered as the "great social leveller". However, at present it is believed that widespread free education alone without equal opportunities and access will result in further inequalities (The First Report of the National Education Commission, 1992).Even after five decades of free education the inequitable allocation of available resources among the urban and the rural schools and the 'big' and the 'small' schools still prevails (National Education Commission Report, 2003).

This same picture can be seen in the teaching of English in the school system as well. It is ironical that English which was introduced as a compulsory second language to be taught in all schools so that 'it would cease to be a badge of social distinction' (Report of the special Education Commission, 1943) continues to be 'an agent of social differentiation' (National Education Commission Report, 2003 :176). The question then is whether it is a poverty of resources that leads to inequality or could there be other reasons which need equal if not more urgent attention? 


\section{Problem Formulation}

According to a study based on case studies of four Sri Lankan schools (Perera, 2002) contrary to the popular belief that it is the bigger schools with more resources that provide more opportunities for language learning, there were better opportunities provided in the smaller disadvantaged schools. However, due to psychosocial problems encountered by the majority of the students in such schools, not much learning appears to be taking place. The students' motivation to learn the language seemed to play a major role in their classroom participation which was also linked to their achievement in the second language. Therefore, there was a need for further studies in disadvantaged school settings.

The purpose of this study therefore was to investigate motivation as a contributing factor in second language learning in a disadvantaged school setting where the students' language learning is influenced by the socio-cultural aspects of learners' identity as well as their psychological and cognitive differences.

In this ethnographic case study in a disadvantaged school setting one of the key challenges that was identified was the 'culture of poverty' and its influence on the teaching learning process of these students. Hence this paper will be based on a subset of data from the main study on motivation and will be guided by two main research questions -

- How did the 'culture of poverty' affect the motivation to learn the second ' language?

- How could motivation be enhanced to promote possibilities of second language learning?

\subsection{Concept of 'culture of poverty'}

Introduced originally by Lewis in 1959, the model of 'culture of poverty' attempted to explain why certain groups did not succeed economically nor, consequently academically. According to this model, certain personal and group attitudes such as dependency and fatalism were produced by the experience of being poor, and these attitudes combined with economic disadvantages added up to a 'culture' which, like all cultures, tended to reproduce itself.

The concept of 'culture of poverty' is also linked with the 'cultural deficit approach' to education (Goldberg cited in Passow,1960). Children coming from disadvantaged homes are deprived of most of the experiences which produce readiness for academic learning either intellectually or attitudinally. The child's view of society is limited by his immediate family and neighbourhood where s/he sees a struggle for survival which sanctions behaviour viewed as immoral by the society at large. S/he has little preparation either for recognizing the importance of schooling in his/her own life or for being able to cope with the kinds of verbal and abstract behaviour which the school will demand. This deficit culture will most often be extended beyond the family to the child's language community and the role models provided by the adult members of his or her social community.

According to Lewis, $(1970 ; 85)$ 'culture of poverty' not only leads to a 'condition of chronic economic poverty,' but also it results in 'cognitive poverty of its 'members', 
instilling a fatalism, as a result of which these 'members' think that they are unable to ever achieve any other way of life.' Although education is one way in which such people could be empowered to develop a sense of self confidence and self worth, children acquire the adult fatalism early and become learned helpless.

\subsection{Learned Helplessness}

Learned Helplessness theory (Seligman, 1994; Gordon and Gordon, 1996) claims that aversive uncontrollable events create three basic deficits in the child motivational, cognitive, and emotional - that destroy the child's desire to learn.

The motivational deficit stops learning by aborting the child's initiation of voluntary responses. The learned helpless child believes s/he has no control over the learning process and, after many failures, gives up trying. It is a cognitive deficit as it is a learned conditioned response. Mere exposure to uncontrollability is not sufficient to make the child helpless but the child must come to expect that outcomes are inevitable. In addition, there is cognitive debilitation and a failure of logical perception and thinking.

The emotional deficit leads to depression and lowered self esteem. Depressed children may have problem behaviour, which they express through anger, aggression, running away, stealing, truancy, and other rebellious acts.

It is the perception the child makes of the failure that leads to the expectancies and the subsequent deficits. It is not just the failure but the way the child sees the failure that is important.

The causal perception is called an attribution and the many attributions the child makes develop into his explanatory style. Seligman (1990) defines explanatory style as the manner in which a person habitually explains why events happen. A continuous negative, pessimistic style leads to depression and learned helplessness. A person's explanatory style is inherited from the parents, but is also shaped by the child's home, school and community environment. It is also formed from negative life crises, such as death, divorce and separation from loved ones (Gordon and Gordon, 1996).

Attributions which lead to a child's explanatory style can be classified along three dimensions: the locus of control, stability, and controllability (Weiner, 1980). The locus of control can be either internal or external.

Stability on the other hand refers either to whether the attribution is a temporary factor relating to a specific factor or to a more lasting factor, relating to a series of tasks.

Controllability judges whether the cause is beyond the person's control or whether s/he can control it.

\subsection{Methodology}

Observation was the principal data gathering technique used in this study in keeping with the characteristics of observational case studies discussed in literature (for example, Bogdan and Biklen, 1998). The observations were conducted in three stages.

"Why not? But I can't" - Influence of a 'culture of poverty'... 25 


\section{Stage 1}

In the first stage, two lessons were observed and field notes taken. The first two observations were trials and the researcher sat through the lessons but they were not recorded. As this teacher was a participant in the researcher's previous research she was used to the researcher being at the back of her class. However, it was thought that the students needed time to get used to the researcher's presence in the class. These preliminary observations were for that reason.

The students were excited about the lessons being recorded. Some of them were keen to get their voices recorded on tape and wanted to listen to the tapes at the end of the lesson. At the beginning, the recordings even became a problem as the teacher found it difficult to control the class as some students would shout out anything, in order to be recorded. However, by the second stage the novelty had worn off and the recordings became part of the lesson.

\section{Stage 2}

The next three lessons were observed, field notes were taken and audio recorded and transcribed by the researcher. By the time the real observations began, the researcher knew all the students in the class by their names. During observations, the researcher had a seating plan of the class with her and each student was identified by two letters. When interactions took place it was indicated on the plan. Furthermore, by then the researcher was able to identify each student by his/her voice on the tape. It was felt that a long period of observation would help the researcher to become 'part of the scene' (Bogdan and Biklen, 1998 ; 88) and the lessons would be as natural as possible.

\section{Stage 3}

The information provided by the teacher regarding the students at the first interview was confirmed by what was seen in the classroom during the early observations. It was revealed that the majority of the students in this class could not understand or even read the English Textbook. It was at this stage that the teacher and the researcher decided that they should start a remedial programme for the students who were very weak in English. The students were divided into two groups. The three better students were to continue with the prescribed textbook while the teacher started teaching the alphabet and introducing the students to reading using the 'Radiant Way Book 1' based on the phonemic method. At first the teacher taught both groups simultaneously by giving some work to the 'better' students while she taught the 'less able' ones and vice versa. However this method was not very successful as most of the time the teacher had to concentrate on working with the 'less able' students and the 'better' students were neglected. As a result the better students became unruly and disturbed the other group as well. This led to the researcher's participation in teaching the better students while the teacher of English continued to teach the 'less able' students the elementary reading and writing skills. This programme continued for three months. At the end of the three months intervention programme the 'treatment' group was given a test. 
Table 1 indicates the marks obtained by the students for the term tests as well as for the special test.

Pseudonyms have been used for the students, teacher and school.

Table 1 -Term test marks - 2001

\begin{tabular}{|l|l|l|l|}
\hline Name & Term 1 & Term 2 & Special \\
\hline 1. Milinda & 85 & 88 & \\
\hline 2. Nilam & 67 & 62 & \\
\hline 3.Ismile & 51 & 52 & \\
\hline 4.Dhammi & 28 & 40 & 75 \\
\hline 5. Surani & 32 & 54 & 88 \\
\hline 6. Manju & $\mathrm{Ab}$ & $\mathrm{Ab}$ & $\mathrm{Ab}$ \\
\hline 7. Jimmy & 15 & 17 & 22 \\
\hline 8. Prabath & 17 & 25 & 62 \\
\hline 9. Sampath & 17 & 18 & 32 \\
\hline 10. Ramani & 65 & & \\
\hline
\end{tabular}

In order to find out whether the culture of poverty affected the motivation to learn, in this instance English which is the second language of the students of the disadvantaged school, it is necessary to understand the culture of the school.

\section{2..4. School}

The school was situated in the midst of a congested slum land. It comprised a single two storied building, which was not well maintained. The wall that was in front of the school was broken and there was no gate. Close to the broken wall was a huge pile of garbage as this was where local residents put their garbage.

The staff comprised eight teachers including the Principal. The Principal who had been at the school for twelve years resided in a small bed-sitter on the school premises. At the time the observations commenced the student population on roll was 100. The average attendance however, was around 50. According to the Principal of the school most students were not regular in their attendance and some rarely came to school. During the course of the observations the attendance dropped even further due to increased bus fares.

Most students who came to Raja were from the nearby shanties. Most of these students came to this school as they were not accepted in any of the other schools in the vicinity due to their social background. There were also 'street children' some of whose education had been intermittently disrupted. The Principal said that he knew the family backgrounds of most of the children. According to him most fathers were either unemployed or involved in illegal business and they sometimes used the children in these activities. The Principal cited this as one reason for the low attendance in the school. According to him, the number of children who attended this school from the neighbourhood was declining. In some of these families at least one parent was working in a Middle East country. As a result they belonged to the 'new rich' in the community and did not want to send their children to this school. On the other hand, the number of 'street children' and children from 'problem homes' was increasing as some NGOs and religious organizations brought such children to this school. As a result, at present there are quite a number of children travelling to school by bus

"Why not? But I can't" - Influence of a 'culture of poverty'... 
and travelling expenses was one reason for low attendance in school.

The school, which was originally a primary school, at the time of the study had classes up to Grade Eight. Yet the number of students had declined. According to the Principal the decline began when the other neighbouring "big" schools started primary classes and Raja no longer became the feeder school. Although there were classes up to Grade Eight, there were only four students in Grade Eight when observations commenced. According to the Principal, after Grade Eight these students were eligible to enter two of the 1C Type single sex schools closest to Raja. However, the students often left school as they found it difficult to adjust to the different culture of these schools. Some of these schools even refused to admit students from Raja. The reason given is that these students may be a bad influence on their own students.

\subsubsection{School's culture - 'a culture of poverty'?}

As the above description depicts Raja was an epitome of 'culture of Poverty' in respect of economic, social and emotional aspects. Thus the school by itself permeated feelings of learned helplessness in the teachers and the students. A majority of the students showed signs of motivational, cognitive as well as emotional deficit in varying degrees. Thus the school appears to be 'instilling a fatalism with reference to any possibility of ever achieving a different way of life'.

Yet can we generalize these characteristics to all the students and label them all as doomed to fail? In the original study the ten students of the Grade Seven class were the 'specific cases'. The initial observations revealed that there were three 'better' students and the rest were 'less able'. Of the 'less able' students some responded to the intervention while the others' motivation did not increase significantly. The following cases from the different categories are discussed in order to find out how the 'culture of poverty' affected motivation.

\subsection{2 "Cases"}

Case 1 - Milinda

Milinda is the best student in the class. His favourite subject is English. However he does well in other subjects as well. Milinda is 12 years old.

Not only is Milinda the best student in the class but he is also the best dressed boy in the class. He is neat in appearance as well as in his work. Compared to other boys in the class he is generally well behaved. However, there are instances when if provoked he fights with others.

Milinda's family background is not that stable. He is a single parent child. Soon after his birth his mother had gone to Baharain as a house maid and is still there. Milinda has been brought up by his grand parents who provide a stable home for him. The mother spends for his education. The grandfather as well as his uncle who lives with the grand parents converse with Milinda at home in English. In addition he is also sent to a tuition class.

He lives about five kilometres away from school and travels to school by bus. He comes to school quite regularly. He said he wants to learn English to go abroad and do a good job. 
Case 2 - Prabath

Prabath is the second in a family of three boys. His father was not employed and according to the teacher not interested in finding employment. Prabath's mother was employed and had to provide the husband every day with fifty rupees, which he used for drinking and smoking. Prabath's elder brother was not working while the younger brother was in the same school. The mother was the sole breadwinner in the family while the father was a drunkard who squandered money and bashed the wife and children.

Prabath's family lived very close to the school in a shanty. He would often be present in school. However, he was not at all interested in studies. During English lessons Prabath would not join in any of the activities. Instead he would disrupt the lesson by fighting with other students. After observing his behaviour for a few days the researcher asked him whether he did not want to learn English. His reply was "Why not ? But I can't".

Case 3 - Jimmy

Jimmy is the second in a family of three boys. His elder brother is married and after a quarrel with the parents had chased the parents away. As a result, Jimmy's parents were begging on the street while Jimmy and his younger brother were in a social service institution. After school both boys used to go to where their parents were begging and go to the institution only late in the evening.

Jimmy was very passive and silent in class. He did not go out of the class even during the interval. Whenever possible either he went to his brother's class or the brother came to his class. Even when a lesson was going on Jimmy's brother would sometimes wait outside the corridor of Jimmy's class.

\section{Problem Solution}

\subsection{Analysis}

Milinda

Milinda has continued to be a good student, gaining the highest marks for English. Thus it could be concluded that he is motivated to learn English. There are several reasons for his sustained motivation. Although he is attending Raja he is not from the immediate environment unlike most of his peers. His family background provides him economic, cognitive as well as emotional support. Thus he is not from a 'deficit academic culture or a 'culture of poverty'. Further he has the additional motivation to learn English as he believes that learning English will enable him to go abroad to join his mother and be employed there.

Milinda is not learned helpless. On the contrary, attributions such as his past successes and his belief in himself motivates him to do well in his studies.

Prabath

Prabath's response "why not? but I can't" indicates that even though he would like to learn English he thinks that he does not have the ability. In contrast to Milinda, Prabath was one of the students who did not even know the alphabet. The tasks in the English text book were too difficult for him. His past failures combined with the environment he comes from had made him learned helpless. He was attributing his failure to inability and to difficulty of the subject. He thought that these conditions were beyond his control. Thus he has learned to be helpless and 
showed signs of motivational and cognitive deficit and at times even emotional deficit as he used to disrupt the work in the class.

However, during intervention when we commenced teaching English by giving very simple tasks, and showed him that he had the ability to learn, Prabath started to improve. At the end of the intervention even though he still found it difficult to follow the prescribed text book for his grade, he scored good marks for the special test given to the 'less able' students.

Even though Prabath came from a culture of poverty which had resulted in an academic deficit, he proved that in spite of these negative conditions motivation to learn can be enhanced.

Jimmy

Jimmy was the worst affected by the 'culture of poverty'. He had learned to be totally helpless. He showed signs of motivational, cognitive as well as emotional deficit. He had learnt that all the adverse effects were stable and uncontrollable.

We were unable to help him through the intervention. The intervention period was too brief to ease the emotional impact. Further, it was beyond our control to help his family problems. On the other hand he was not making any attempt to get away from the adverse conditions as he attributed his failures to outside forces which he has learned to be uncontrollable and stable.

Thus it can be concluded that Jimmy represents the 'members' of a culture of poverty whose continuous negative, pessimistic style leads to depression and learned helplessness. His explanatory style is inherited from the parents, but is also shaped by his home, school and community environment. It is also formed from negative life crises. (Gordon and Gordon, 1996).

As discussed by Gardner (1985) the social and cultural milieu in which learners grow up determines their beliefs about language and culture. The analysis of the family backgrounds of the three students indicated that in this study also the students' family backgrounds influenced their beliefs about language learning. Even though the socio economic backgrounds of most of the students at Raja were similar, a few students like Milinda whose family members were conversant in English had more positive attitudes towards the English language and about learning it. Further, compared to the other students Milinda did not come from a 'culture of poverty' On the other hand, Prabath and Jimmy came from adverse family backgrounds and their motivation to learn was low.

Thus the findings of this study seem to support the view that parents' beliefs, expectations, confidence in children's abilities and a supportive affective family culture contribute in shaping student motivation to learn the second language.

However, there was a significant difference in the motivation of Prabath and Jimmy after the intervention.

As Table 1 indicates, Prabath's test scores increased considerably in the special test whereas there was not much difference in Jimmy's marks. Thus it could be concluded that even in a disadvantaged culture of poverty students' motivation can be enhanced to promote possibilities of second language learning.

In section 3.2 some suggestions that emerged from the study for enhancing motivation are discussed. 


\subsection{Suggestions for enhancing student motivation}

The findings of this study support the views expressed by other researchers such as Ford $(1992: 202)$ that there are 'no magical Buttons that can be pushed to make people want to learn'. Similar views have also been made by Dörnyei, (2001a) and McCombs and Pope (1994) who claim that it is highly unlikely that everybody can be motivated to learn but most students' motivation can be 'worked on'. The findings of this study indicate that in order to 'work on' student motivation it is necessary to understand their individual learner differences - not only personality differences but also the attributions they make of their learning experiences both present as well as past.

\section{Changing attributions}

The success of the intervention could be due to identifying the causes for low motivation and changing the attributions or explanatory style of the students. Most of the 'less able' students who did well after the intervention were students who attributed their past failures to internal factors such as low ability and external factors such as task difficulty and low socio economic conditions. During the intervention these students were shown that their locus of control which they thought was stable and uncontrollable is in fact controllable and unstable. Thus the findings of this study also support the claim (Gordon and Gordon, 1996 : Seligman, 1990; 2001) that student motivation can be enhanced by changing negative explanatory styles and their locus of control.

\section{Curriculum}

'Task difficulty' seemed to be a common focus of attention in most students' attributions for failure. It could also be concluded that the English language curriculum does not seemed to be catering very much to the needs of the students from disadvantaged backgrounds. This could be one reason for low motivation for learning English among the socio culturally marginalized students. The findings of this study also support the view that the same textbooks are not suitable to be used in all learning contexts. Student heterogeneity is a problem in teaching any subject. However, this problem is more complex in the ESL classroom as exposure to the second language which is an important variable in language learning differs depending on the students' background. As has been discussed, student heterogeneity has been a problem throughout the history of ESL in Sri Lanka and as has been argued before (for example, De Lanerolle Commission Report, 1973; De Silva, 1979; Karunaratne, 1990; Perera, 2002) a stratified syllabus to cater for at least three ability levels of students needs to be developed. The heterogeneity of the student population in the ESL classrooms clearly indicates that using the same learning materials in all the classrooms is a problem.

\section{Assessment}

The domination of examinations on what happens in the classrooms suggests that assessment is clearly an issue in motivating students to learn the second language. The mismatch between the product based assessment of reading, writing and grammar and the intentions of the EED materials to teach pupils communicative abilities with considerable emphasis on oral skills has been highlighted by Alderson, 1992. Although school based assessment has been 
introduced and teachers are expected to design their own tests and to assess students' ability to use all four language skills, teachers seemed to be getting mixed messages from the administrators regarding assessment. The test papers administered by the Education Department at the end of the school term continue to be in place. Thus, if what happens in the classrooms is to be more flexible, the assessment procedures also need to change, giving the schools more freedom to design their own tests to meet the needs of their students.

\section{Teacher training}

The findings of this study suggest that despite the fixed syllabus the teacher was able to adapt the learning materials to suit the needs of her students. As her comments indicated, in spite of recent professional training she did not know how to adapt the materials until she was involved in this research. Thus teachers should be informed of the theoretical underpinnings of both ESL and Psychology and have more opportunities during their training to put these theories into practice.

This study also indicates that teachers need regular retraining in the use of the learning materials and the need for better monitoring of teacher preparation programs. As stated in the Reforms in General Education, the Ministry of Education has accepted as a matter of policy that all teachers should undergo periodical in -service education programs. Teachers' Centres have been established throughout the country. These Teacher Centres can be used to assist teachers to try out new ideas and share their experiences in motivating students to learn the second language.

\section{Additional learning materials}

The use of additional learning materials helped to motivate the students and resulted in better student participation. Thus, the use of learner made as well as authentic materials and also the possibility of doing projects, preparation of charts, and introduction of songs and drama may result in better student motivation and make learning English more pleasurable. The observations at Raja indicated that students were more responsive to language learning when an element of competition through activities such as games was introduced into the lesson. The students' enthusiasm to be audio recorded, evidenced throughout the study, suggests that the use of audio materials even occasionally may facilitate motivation in the class and help in language development.

A pleasant and supportive atmosphere in the classroom was another motivational tool that helped enhance motivation. Language learning is one of the most face threatening subjects learnt in an institutional setting because of the pressure of having to operate using an alien and restricted language code. Language anxiety is claimed to be a powerful factor hindering L2 learning achievement (Mclntyre, 1999; Young, 1999). Therefore, it is essential that a pleasant and supportive classroom atmosphere is created. As Scheidecker and Freeman (1999, p. 138) describe it such a classroom is an 'emotional safe zone' where 'one gets an overwhelming sense that the students shed emotional baggage at the doorway'.

The findings of this study clearly indicated that even though the school was situated in a very disadvantaged setting in terms of physical resources, both the 
principal of the school and the teacher of English contributed very much in providing a supportive learning environment.

\section{Conclusion}

In conclusion, it could be said that the findings of this study clearly indicate that at Raja the students' motivation to learn the second language was complex. The findings support the view that several factors such as the social cultural milieu, students' need for achievement and their prior experiences of learning English contribute to their motivation towards learning the second language. Thus it could be concluded that in this disadvantaged school setting, students' motivation to learn the second language is 'multifactorial'. On the other hand, students' motivation to learn the second language was causally related to achievement. Thus the contribution of motivation on achievement differed in each student depending on the intensity and type of variables that impacted on motivation.

In finding an answer to the question how can motivation be enhanced to promote possibilities of second language learning, we could agree with Scheidecker and Freeman (1999, p.117) that 'unfortunately, and realistically, motivating students yesterday, today and tomorrow will never be a singular or simplistic process'. As was evident in this study not only did the teacher have to initiate motivation but also to maintain it. There were instances where it was very difficult to sustain motivation. Sustaining motivation was even more difficult due to the 'culture of poverty' of the home and community. This fact is further supported by the claim (Ushioda, 1996, p.240) that 'within the context of institutional learning, especially, the common experience would seem to be motivational flux rather than stability'. Thus, even though there is no single way of motivating students the findings of the intervention programme indicate that a combination of the above mentioned motivational tools can be used to enhance student motivation to learn the second language.

\section{References}

Alderson, C. 1992. New syllabus O - Level English. Shiksha, 21 - 24.

Bogdon, R. \& Biklen, S. 1998. Qualitative research for education- An introduction to theory, London : Allyn and Bacon.

De Lanerolle Commission Report. 1973. Report of the committee of inquiry into the teaching of English in the schools of Sri Lanka. Colombo: Government Printing Press.

De Silva, S. F. 1960. Report of the committee of inquiry into the teaching of English in Ceylon schools. Sessional Paper V. Colombo: Government Publication Bureau.

Dörnyei, Z. 2001. Motivational strategies in the language classroom, Cambridge: Cambridge University Press.

Gardner, R.C 1985. Social psychology and second language learning: The role of attitudes and motivation, London: Edward Arnold.

Karunaratne, G. 1990. English teacher effectiveness with special reference to the use of the communicative approach, Maharagama: National Institute of Education.

"Why not? But I can't" - Influence of a 'culture of poverty'... 
Lewis, O. 1978. The Culture of Poverty, New York: Random House.

Mc. Combs, B. \& Pope, J. 1994. Motivating Hard to reach students, Washington : American Psychological Association.

Maclntyre, P. 1999. 'Language anxiety : a review of the research for language teachers' in Affect in foreign language and second language learning, D.J. Young (ed.) Boston : McGraw-Hill,24:45.

National Education Commission Report. 2003 Proposals for a National Policy framework on General Education in Sri Lanka, Colombo: National Education Commission.

Passow, 1960. Education in depressed areas , New York: Random House.

Perera, M. 2002. Role of classroom interaction in second language acquisition in Sri Lanka. Unpublished Ph.D. Dissertation, University of Wollongong.

Report of the Special Committee on Education. 1943. Sessional Paper xxiv. Colombo: Government Printing Press.

Report of the Presidential Commission on Youth. 1990. Youth Commission Report. Colombo: Government Printing Press.

Reforms in General Education. 1997. Colombo : National Education Commission.

Scheidecker, D. and Freeman, D. 1999. Bringing out the best in students : How legendary teachers motivate kids, Thousand Oaks, CA :Corwin Press.

Seligman, M. 1975. Helplessness: on depression, development, and death, San Francisco: W.H. Freeman.

Seligman, M. 1990. Learned Optimism, New York: Knopf.

Seligman, M. 1994. What you can change and what you can't: the complete guide to successful self-improvement, New York: Knopf.

The First Report of the National Education Commission. 1992. Sessional Paper V. Colombo: Government Printing Press.

Ushioda, E. 1996. 'Developing a dynamic concept of motivation' in Language, education and society in a changing world, Hickey, T. \& Williams, J. (eds.) Multilingual Maters, Clevedon.239- 45.

Weiner, B. 1990. 'Attribution theory' in Human motivation. New York, NJ: Erlbaum. pp.275-326.

Young, D. (ed.) 1999. Affect in Language learning , Boston : McGraw- Hill. 